J. Clin. Chem. Clin. Biochem.

Vol. 24, 1986, pp. $161-166$

(C) 1986 Walter de Gruyter \& Co.

Berlin - New York

\title{
Serum Apolipoproteins A-I, A-II and B in Hepatic Metastases Comparison with other Liver Diseases: Hepatomas and Cirrhosis
}

\author{
By Houda Hachem
}

Laboratoire de Biochimie Appliquée, Faculté des Sciences Pharmaceutiques, Toulouse

Gilles Favre, Gérard Raynal

Laboratoire de Biochimie - Groupe de Recherches en Cancérologie, Centre Claudius Regaud, Toulouse

Gisèle Blavy

Centre de Transfusion Sanguine de Dakar, République du Senegal

Pierre Canal

Laboratoire de Biochimie - Groupe de Recherches en Cancérologie, Centre Claudius Regaud, Toulouse

Georges Soula

Laboratoire de Biochimie - Groupe de Recherches en Cancérologie, Centre Claudius Regaud, Toulouse Laboratoire de Biochimie Appliquée, Faculté des Sciences Pharmaceutiques, Toulouse

(Received April 1/December 9, 1985)

Summary: Serum concentrations of lipids and apolipoprotein A-I, A-II and B were determined in patients with hepatic metastases of colorectal cancer, with primary liver cancer and with cirrhosis.

In all three liver diseases, the HDL fraction and apolipoproteins A-I and A-II showed significantly low values, while apolipoprotein B was only increased in hepatic metastases.

The decrease of apolipoprotein A-II levels was more prominent in cirrhosis, thereby enhancing the A-I/AII ratio. This ratio is decreased in metastasis and normal in hepatomas.

In patients with hepatic metastases a correlation was observed between alkaline phosphatase and apolipoprotein A-II $(p<0.05)$, and between $\gamma$-glutamyltransferase and the A-I/A-II ratio $(p<0.05)$.

The. present work suggests that determination of apolipoproteins and lipids of the HDL fraction offers a new approach to the study of liver diseases.

Apolipoprotein A-I, A-II und B im Serum bei Lebermetastasen - Vergleich mit anderen Lebererkrankungen: Hepatom und Cirrhose

Zusammenfassung: Die Konzentrationen der Lipide und der Apolipoproteine A-I, A-II und B wurden im Serum von Patiẹten mit Lebermetastasen bei colorectalem Carcinom, mit primärem Lebercarcinom und mit Cirrhosen bestimmt.

Bei allen drei Lebererkrankungen zeigten die HDL-Fraktion und die Apolipoproteine A-I und A-II signifikant niedrige Werte, während bei Lebermetastasen allein Apolipoprotein B erhöht war. 
Der Abfall von Apolipoprotein A-II war deutlicher bei Cirrhose, wobei der A-I/A-II-Quotient erhöht war. Dieser Quotient ist bei Metastasen erniedrigt und bei Hepatomen normal.

Bei Patienten mit Lebermetastasen wurde eine Korrelation zwischen alkalischer Phosphatase und Apolipoprotein A-II $(p<0,05)$ sowie zwischen $\gamma$-Glutamyltransferase und dem A-I/A-II-Quotienten $(p<0,05)$ beobachtet.

Die vorgelegten Ergebnisse weisen darauf hin, daß die Bestimmung von Apolipoproteinen und Lipiden der HDL-Fraktion einen neuen Zugang zur Untersuchung von Lebererkrankungen eröffnet.

\section{Introduction}

Liver cells seem to be partially involved in the synthesis of apolipoproteins A-I and A-II $(1,2)$, the two major polypeptides of HDL fraction $(3,4)$. Most HDL molecules contain both A-I and A-II, while some of them contain only A-I (5). The proportions of the two apolipoproteins and the value of the A-I/ A-II ratio therefore represent clinically interesting parameters.

Apolipoprotein $\mathrm{B}$, the major protein moiety of LDL $(6,7)$ and a binding ligand for cellular receptors $(8)$, is also synthesized by liver or intestine (9).

The liver is the major contributor of circulating lipoproteins and alterations in hepatic function may influence the plasma lipoprotein profile. Several reports $(10,11)$ have shown that liver diseases are characterized by distinct apolipoprotein profiles: Cordova et al. (12) and Fujii et al. (2) reported decreases of serum apolipoprotein A-I and A-II in acute hepatitis, cirrhosis and cholestasis.

However, the data available on apolipoprotein profiles in hepatomas and hepatic metastases are limited.

This study describes changes in the levels of cholesterol, phospholipid, total HDL and apolipoproteins A-I, A-II and B in cases of liver metastases of colorectal adenocarcinoma. These results are compared with those obtained in two other liver deseases: hepatomas and cirrhosis. We also investigated possible correlations between the liver status (expressed by serum $\gamma$ glutamyltransferase and alkaline phosphatase catalytic activities, commonly recognized as sensitive indices of these hepatic disorders $(13,14))$ and apolipoprotein levels.

\section{Materials and Methods \\ Clinical populations}

Four populations of subjects were studied. The diagnosis of hepatic disease was microscopically confirmed on biopsies in all cases.
Twenty subjects suffering from hepatic metastases of colorectal adenocarcinoma were investigated. All patients had been cured of their primary carcinoma and were free from concomitant bone involvement at the time of serum determinations.

The results obtained on this group were compared with those of three other populations:

Twenty two Senegalese black patients suffering from hepatocarcinomas, twenty two cases of cirrhosis without neoplastic disease and a control group including sixty-eight healthy subjects without hepatic disorder.

Blood samples were withdrawn from all subjects after a 12 to $14 \mathrm{~h}$ overnight fast. Serum samples were stored for one or two weeks frozen at $-20^{\circ} \mathrm{C}$ with $0.05 \%$ of sodium azide. Evaluations were made after the same time for all populations.

\section{Analytical methods}

In all populations, liver status was investigated by the evaluation of serum aspartate aminotransferase, alanine aminotransferase, lactate dehydrogenase, alkaline phosphatase and bilirubin (with ROCHE Diagnostica reagents on the Cobas-bio centrifugal analyser).

Total cholesterol and total phospholipids were determined by enzymatic methods $(15,16)$ on the Cobas-bio analyser.

HDL-cholesterol and HDL-phospholipids were evaluated, according to Grove et al. (17) after LDL and VLDL precipitation by sodium phosphotungstate, $\mathrm{MgCl}_{2}$ at $\mathrm{pH} 6.15$.

\section{Determination of apolipoproteins}

Apolipoproteins A-I and B were simultaneously evaluated by electro-immunodiffusion on commercially prepared agarose gel plates (Apofilms A-I, B SEBIA) according to Fruchart et al. (18).

Apolipoprotein A-II was evaluated by immunoturbidimetric assay on the Cobas-bio analyser (19), using commercially monospecific antiserum to human apolipoprotein A-II purchased from Immuno-Diagnostica. The corresponding purified human apolipoprotein A-II (i. e., apolipoprotein A-II, 5.18 to $6.61 \mathrm{~g} / \mathrm{l}$ ) was used as standard and supplied as "reference standard" by Immunofrance. Prior to immunoturbidimetric assay the serum samples were diluted to $1: 80$ in a $9 \mathrm{~g} / \mathrm{l} \mathrm{NaCl}$ solution containing $5 \mathrm{ml} / \mathrm{l}$. Tween 20 .

The apolipoprotein A-II assay was linear over the range of 0.002 to $0.011 \mathrm{~g} / \mathrm{l}$. Intra- and inter-assay coefficients of variation were less than $5 \%$.

\section{Statistical study} Comparison of means was carried out by the Mann-Withney
$\mathrm{U}$ test. 
Simple linear regression analysis was performed to identify significant $(p<0.05)$ relationships between apolipoprotein levels and liver biochemical variables parameters $(\gamma$-glutamyltransferase, alkaline phosphatase). When necessary appropriate log transformations were carried out to normalize distributions and to stabilize variances.

\section{Results}

Table 1 summarizes the lipid profiles (total cholesterol, total phospholipids, cholesterol and phospholipids of HDL fractions) obtained in the different populations. In liver metastases, total cholesterol is increased, total phospholipid is normal, but HDL-cholesterol and HDL-phospholipid are diminished $(\mathrm{p}<$ $0.001)$. Hepatomas and cirrhosis are characterized by a decrease of all parameters.

The levels of serum apolipoproteins A-I, A-II and B in the four populations investigated are summarized in table 2. The mean and SD of the apolipoprotein A-I level in healthy subjects was $1.31 \pm 0.25 \mathrm{~g} / \mathrm{l}$. In the three liver diseases, apolipoprotein A-I levels decrease markedly (fig. 1,a).

The mean and SD of the A-II level in normal subjects was $0.44 \pm 0.08 \mathrm{~g} / 1$. This parameter is not disturbed in metastases, but decreases in cirrhosis $(p<0.001)$ and hepatomas $(p<0.01)$ (fig. 1,b).
The A-I/A-II ratio (2.98 \pm 0.39 in normal subjects) decreases to $1.95 \pm 0.76$ in metastases, is normal in hepatomas and rises to $5.54 \pm 4.26$ in cirrhosis (fig. 1,c).

The apolipoprotein B levels increase in metastases $(1.39 \pm 0.48 \mathrm{~g} / \mathrm{l})$ but decrease in hepatomas and cirrhosis (fig. 1,d).

The study of the correlation between liver status and apolipoprotein profiles shows significant correlations between $\gamma$-glutamyltransferase and the A-I/A-II ratio, and between alkaline phosphatase and apolipoprotein A-II in metastases. No relationship is noticed in hepatomas; in cirrhosis, $\gamma$-glutamyltransferase and alkaline phosphatase are significantly correlated with apolipoprotein B $(p<0.01)$, and $\gamma$-glutamyltransferase with apolipoprotein A-II or the A-I/A-II ratio (tab. 3).

\section{Discussion}

Since the liver is one of the major sites for the formation of apolipoproteins and lipoproteins, some, if not most, of the pathologic events affecting this organ ought to be reflected in changed concentrations of plasma apolipoproteins.

Tab. 1. Comparative studies of lipid components (mean \pm SD) between pathological populations and control group.

\begin{tabular}{llllll}
\hline & & $\begin{array}{l}\text { Total cholesterol } \\
(\mathrm{mmol} / \mathrm{l}) \\
\text { mean } \pm \mathrm{SD}\end{array}$ & $\begin{array}{l}\text { HDL cholesterol } \\
(\mathrm{mmol} / \mathrm{l}) \\
\text { mean } \pm \mathrm{SD}\end{array}$ & $\begin{array}{l}\text { Total phospholipids } \\
(\mathrm{g} / \mathrm{l}) \\
\text { mean } \pm \mathrm{SD}\end{array}$ & $\begin{array}{l}\text { HDL phospholipids } \\
(\mathrm{g} / \mathrm{l}) \\
\text { mean } \pm \mathrm{SD}\end{array}$ \\
\hline Controls & $\mathrm{n}=68$ & $5.68 \pm 1.00$ & $1.44 \pm 0.36$ & $2.08 \pm 0.29$ & $1.21 \pm 0.21$ \\
Metastases & $\mathrm{n}=20$ & $5.83 \pm 2.06^{* *}$ & $0.70 \pm 0.40^{* * * *}$ & $20.7 \pm 0.46 \mathrm{NS}$ & $0.72 \pm 0.30^{* * * *}$ \\
Hepatomas & $\mathrm{n}=22$ & $4.86 \pm 2.39^{* *}$ & $0.54 \pm 0.32^{* * * *}$ & $1.86 \pm 0.66^{* *}$ & $0.59 \pm 0.23 * * *$ \\
Cirrhosis & $\mathrm{n}=22$ & $4.07 \pm 1.54^{* * *}$ & $0.95 \pm 0.69^{* * *}$ & $1.62 \pm 0.51^{* * *}$ & $0.78 \pm 0.29 * * * *$ \\
\hline
\end{tabular}

$\mathrm{NS}=$ not significant, ${ }^{* *}=\mathrm{p}<0.05, * * *=\mathrm{p}<0.01 ; * * * * \mathrm{p}<0.001$

Tab. 2. Comparative studies of apolipoproteins, A-I/A-II ratio (mean \pm SD) between pathological populations and control group.

\begin{tabular}{llllll}
\hline & & $\begin{array}{l}\text { Apolipoprotein A-I } \\
(\mathrm{g} / \mathrm{l})\end{array}$ & $\begin{array}{l}\text { Apolipoprotein A-II } \\
(\mathrm{g} / \mathrm{l})\end{array}$ & $\begin{array}{l}\text { Apolipoprotein B } \\
(\mathrm{g} / \mathrm{l})\end{array}$ & A-I/A-II \\
\hline Controls & $\mathrm{n}=68$ & $1.31 \pm 0.25$ & $0.44 \pm 0.08$ & $1.09 \pm 0.27$ & $2.98 \pm 0.39$ \\
Metastases & $(1) \mathrm{n}=20$ & $0.69 \pm 0.27^{* * * *}$ & $0.38 \pm 0.15 \mathrm{NS}$ & $1.39 \pm 0.48^{* *}$ & $1.95 \pm 0.76^{* * * *}$ \\
Hepatomas & $(2) \mathrm{n}=22$ & $0.80 \pm 0.43^{* * *}$ & $0.34 \pm 0.15^{* * *}$ & $0.56 \pm 0.35^{* * * *}$ & $2.70 \pm 1.63 \mathrm{NS}$ \\
Cirrhosis & $(3) \mathrm{n}=22$ & $0.71 \pm 0.31^{* * * *}$ & $0.18 \pm 0.13^{* * * *}$ & $0.73 \pm 0.26^{* * * *}$ & $5.54 \pm 4.26$ \\
\hline
\end{tabular}

NS = not significant, $* *=p<0.05, * * *=p<0.01, * * * *=p<0.001$ 

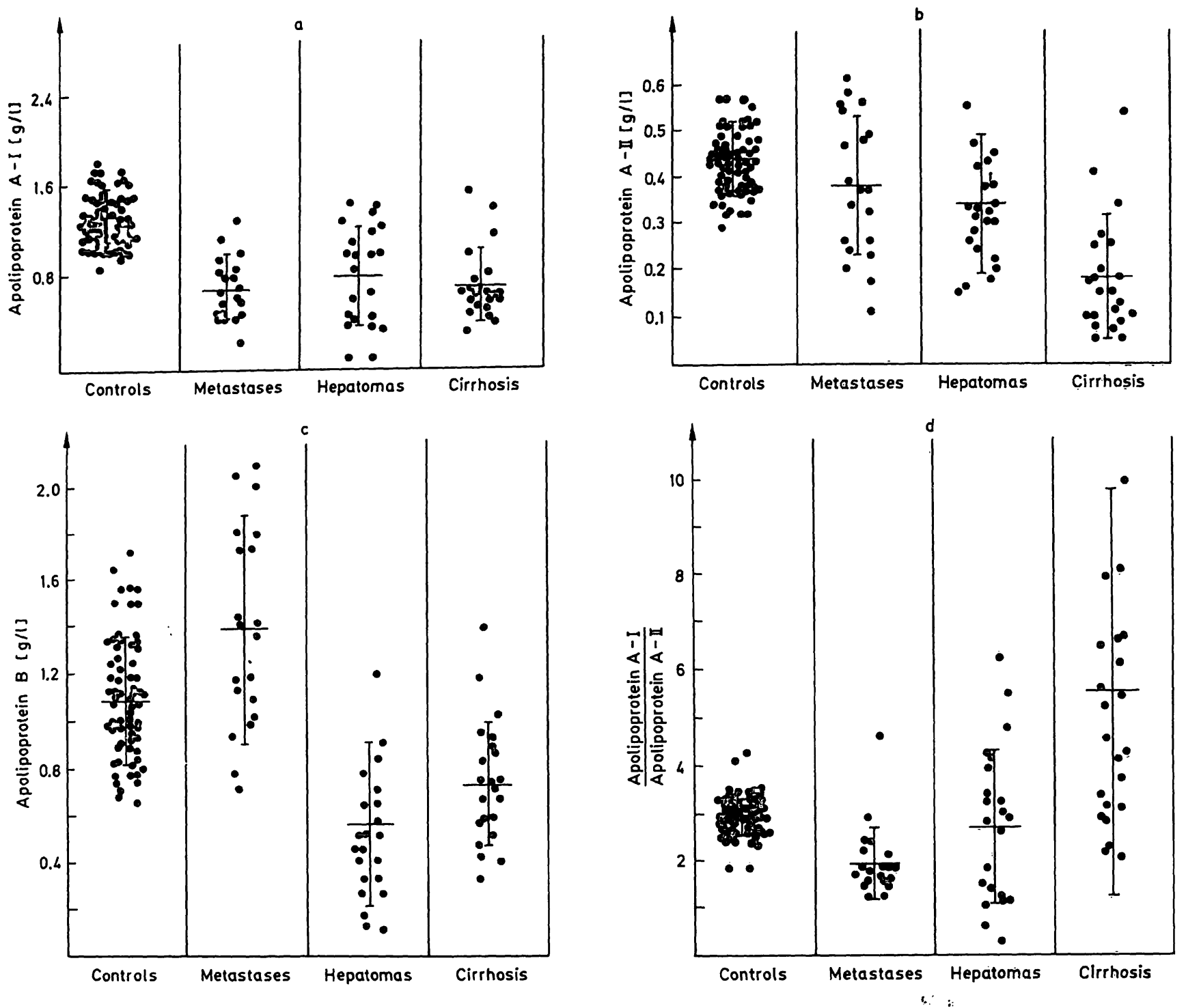

Fig. 1. Mean \pm SD of apolipoprotein A-I, A-II and B serum levels, and A-I/A-II ratio in pathological populations investigated and of control group.

Tab. 3. Degree of linear association ( $r$ ) among $\gamma$-glutamyltransferase and alkaline phosphatase with apolipoproteins and A-I/A-II ratio in the three liver diseases.

\begin{tabular}{llll}
\hline Parameters & $\begin{array}{l}\text { Metastases } \\
\mathbf{n}=20\end{array}$ & $\begin{array}{l}\text { Hepatomas } \\
\mathbf{n}=22\end{array}$ & $\begin{array}{l}\text { Cirrhosis } \\
\mathbf{n}=22\end{array}$ \\
\hline$\gamma$-Glutamyltransferase - Apolipoprotein A-I & 0.087 & 0.151 & 0.225 \\
Alkaline phosphatase - Apolipoprotein A-I & 0.302 & 0.036 & 0.098 \\
$\gamma$-Glutamyltransferase - Apolipoprotein A-II & 0.387 & 0.090 & $0.450^{*}$ \\
Alkaline phosphatase - Apolipoprotein A-II & $0.448^{*}$ & 0.113 & 0.067 \\
$\gamma$-Glutamyltransferase - A-I/A-II & $0.466^{*}$ & 0.111 & 0.408 \\
Alkaline phosphatase - A-I/A-II & 0.271 & 0.003 & 0.017 \\
$\gamma$-Glutamyltransferase - Apolipoprotein B & 0.056 & 0.232 & $0.549^{* *}$ \\
Alkaline phosphatase - Apolipoprotein B & 0.025 & 0.288 & $0.551^{* *}$ \\
\hline
\end{tabular}

$*=\mathrm{p}<0.05$

$* *=p<0.01$

In the present investigation, we attempted to elucidate the lipid abnormalities in patients with hepatic metastases, giving special consideration to changes in apolipoproteins compared to those occurring in two other liver diseases.
The decrease of serum apolipoprotein A-II levels in these three liver diseases seems to characterize the liver status. Nestel et al. (20) demonstrated that the reduced concentration of apolipoprotein A-I in alcoholic hepatitis is due, not to diminišhed synthesis, but 
to rapid degradation. Other hypotheses have been formulated to explain the decrease of HDL and apoprotein in liver diseases: Luoma et al. $(21,22)$ showed that in subjects with liver diseases, and a reduced amount of healthy parenchyma, low HDL levels may reflect impaired hepatic synthesis of HDL constituents.

An abnormal lipoprotein, apolipoprotein E-rich HDL, was observed in patients with liver disease (23), in patients with lecithin-cholesterol acyltransferase deficiency (24) and in patients with alcoholic hepatitis (25) in whom lecithin-cholesterol acyltransferase activities are low $(26,27)$.

Our results show a decrease of HDL cholesterol in the three liver diseases.

This parameter was determined after precipitation with phosphotungstic acid/magnesium reagent which precipitates apolipoprotein E-rich HDL (28). Consequently, the HDL cholesterol levels determined in this study did not contain this apolipoprotein E-rich HDL.

The increase of HDL cholesterol observed by Koga et al. (29) in patients with primary biliary cirrhosis, may be due to the rise of apolipoprotein E-rich HDL. These data are not in disagreement with our results, which showed a decrease of HDL cholesterol in the liver diseases. Elsewhere, these authors could not detect apolipoprotein E-rich HDL in any patient with acute viral hepatitis, alcoholic hepatitis, liver cirrhosis or obstructive jaundice.

The simultaneous decrease of apolipoprotein A-I and HDL cholesterol suggest that this perturbation only affects the fraction of HDL which does not contain apolipoprotein $\mathrm{E}$. In these conditions, the decrease of apolipoprotein A-I (activator of lecithin-cholesterol acyltransferase), might induce a decrease of lecithincholesterol acyltransferase and an increase of apolipoprotein E-rich HDL (26).

The apolipoprotein A-II level is markedly diminished in cirrhosis, enhancing the interest of the A-I/A-II ratio. In fact, this ratio is two fold increased in cirrhosis, decreased in metastasis and normal in hepa- tomas. As suggested by Fujji et al. (2), changes in the relative amounts of HDL subfractions could also account for changes in the A-I/A-II ratio, since the ratio is greater in $\mathrm{HDL}_{2}$ than in $\mathrm{HDL}_{3}$. Possibly decreases in $\mathrm{HDL}_{3}$ could be more prominent than decreases in $\mathrm{HDL}_{2}$ in cirrhosis. Tateossian et al. (30) describe a similar increase of the A-I/A-II ratio in alcoholic cirrhosis, but the reason for the discrepancies observed between cirrhosis and primary and metastatic cancers is not elucidated.

The most distinctive feature of apolipoprotein changes seen in patients with hepatic metastases is the increase of apolipoprotein B levels. This rise was also noticed by Alaupovic (10) who studied only 7 cases of hepatic metastases.

This apolipoprotein $\mathrm{B}$ mediates the interaction between VLDL, LDL and the apolipoprotein B, E receptors of various cells. These receptors interact not only with LDL containing apolipoprotein $\mathrm{B}$, but also with HDL containing apolipoprotein $\mathrm{E}(21,22$, $23,24)$. It has been shown that apolipoprotein Band apolipoprotein E-containing lipoproteins have similar roles in regulating intracellular cholesterol metabolism. Thus, in patients with hepatic metastases and microcholestasis confirmed by a correlation between alkaline phosphatase and A-II $(\mathrm{p}<0.05)$, and between $\gamma$-glutamyltransferase and the A-I/A-II ratio $(p<0.05)$, it may be supposed that there is an increase of apolipoprotein $\mathrm{E}$ implicated in ligandreceptor binding, which displaces apolipoprotein $\mathrm{B}$ receptor and consequently increases apolipoprotein $B$ levels in patients with hepatic metastases.

To elucidate this hypothesis, studies are in progress to evaluate serum apolipoprotein $E$ levels and their relationship with apolipoprotein E-rich HDL.

The presented results suggest that determination of serum apolipoproteins and lipid fractions of HDL offers a new approach to the study of liver diseases. In fact, they are characterized by low levels of the HDL components, A-I and A-II. Apolipoprotein B levels might be used to differentiate between cirrhosis, hepatomas (hepatocellular dysfunction) and metastatic liver involvement.

\section{References}

1. Glikman, R. M., Green, P. H. R., Lees, R. S. \& Tall, A. (1978) N. Engl. J. Med. 299, 1424-1427.

2. Fujii, S., Koga, S., Shono, T., Yamamoto, K. \& Ibayashi, H. (1981) Clin. Chim. Acta 115, $321-331$.

3. Scanu, A., Thoth, J., Edelstein, C., Koga, S. \& Stiller, E. (1969) Biochemistry 8, 3309-3316.

4. Shore, B. \& Shore, V. (1969) Biochemistry 8, 4510-4516.

5. Albers, J. J. \& Aladjem, F. (1971) Biochemistry 10, $3436-3442$.

6. Kane, J. P., Sata, T., Hamilton, R. L. \& Havel, R. J. (1975) J. Clin. Invest. 56, 1622-1634.

7. Kane, J. P., Hardman, D. A. \& Paulus, H. E. (1980) Proc. Nat. Acad. Sci. U.S. A. 77, 2465-2469.

8. Goldstein, J. L. \& Brown, M. S. (1975) Am. J. Med. 58, 147-150.

9. Drouin, P., Antoine, J. M., Pointel, J. P., Louis, J. \& Debry, G. (1983) Annales d'Endocrinologie (Paris) 44, 51 - 58.

10. Alaupovic, P. (1980) Ann. Biol. Clin. 38, 83-93. 
11. Chabrier, G., Schlienger, J. L., Fuffoel, M., Laidoudi, A., Simon, C. \& Imler, M. (1983) La Presse Med. 12, 739-742.

12. Cordova, C., Musca, A., Violi, F., Alessandri, C. \& Luliano, L. (1984) Clin. Chim. Acta 137, 61-66.

13. Burlina, A., Plebani, M., Dechecchi, C., Zaninotto, M., Farinati, F. \& Naccarato, R. (1983) Clin. Biochem. 16, 346-349.

14. Lum, G. \& Gambino, S. R. (1972) Clin. Chem. 18, $358-361$.

15. Seigler, L. \& Wu, W. T. (1981) Clin. Chem. 27, 838-841.

16. Ikayama, M., Itoh, S., Nagazaki, T. \& Tanimizu, I. (1977) Clin. Chim. Acta 79, 93-96.

17. Grove, T. H. (1979) Clin. Chem. 25, 560-564.

18. Fruchart, J.-C., Kora, I., Cachera, C., Clavey, V., Duthilleul, P. \& Moschetto, Y. (1982) Clin. Chem. 28, 59-62.

19. Hachem, H., Raynal, G., Hamza, M., Canal, P. \& Soula, G. (1985) Clin. Biochem. 18, 332-337.

20. Nestel, P. J., Tada, N. \& Fidge, N. H. (1980) Métabolism 29, $101-103$.

21. Luoma, P. V., Arranto, A. J., Ehnholm, C. \& Sotaniemi, E. A. (1981) Res. Commun. Chem. Pathol. Pharmacol. 33, $163-173$.

22. Luoma, P. V., Sotaniemi, E. A., Pelkonen, R. O., Arranto, A. \& Ehnholm, C. (1982) Eur. J. Clin. Pharmacol. 23, $275-282$.

23. Miyata, Y., Kòga, S. \& Ibayashi, H. (1983) Acta Hepatol. Jpn. 24, 167-173.
24. Mitchell, C. D., King, W. C., Applegate, K. R., Forte, T., Glomset, J. A., Norum, K. R. \& Gjone, E. (1980) J. Lipid Res. 21, 625-634.

25. Weidman, S. W., Ragland, J. B. \& Sabesin, S. M. (1982) J. Lipid Res. 23, 556-569.

26. Harry, D. S., Day, R. C. \& Bwen, J. S. (1978) Scand. J. Clin. Lab. Invest. 38, Suppl. 150, $223-227$.

27. Sabesin, S. M., Hawkins, H. L., Kuiken, L. \& Ragland, J. B. (1977) Gastroenterology 72, 510-518.

28. Gibson, J. C., Rubinstein, A. \& Brown, W. V. (1984) Clin. Chem. 30, 1784-1788.

29. Koga, S., Miyata, Y. \& Ibayashi, H. (1985) Hepatology 5, 286-292.

30. Tateossian, S., Peynet, J., Legrand, A., Collet, B., Rossignol, J. \& Rousselet, F. (1984) Acta Pharmacol. Biol. Clin. $3,373-376$.

31. Mahley, R. W. (1982) In: Medical clinics of North America: Lipid disorders (Havel, R. J., ed.) Vol 66. W. B. Saunders, Philadelphia, pp. 375-402.

32. Mahley, R. W. (1978) In: Disturbances in lipid and lipoprotein metabolism (Dietschy, J. M., Gotto, A. M. \& Ontko, J. A., eds.) Amer. Physiol. Soc. Bethesda, pp. 181-197.

33. Innerarity, T. L. \& Mahley, R. W. (1978) Biochemistry 17, 1440-1447.

34. Pitas, R. E., Innerarity, T. L., Amold, K. S. \& Mahley, R. W. (1979) Proc. Natl. Acad. Sci. U. S. A. 76, $2311-2315$.

\section{Georges Soula}

Centre Claudius Regaud

20-24, Rue du Pont-Saint-Pierre

F-31052 Toulouse Cedex 